\title{
Allogeneic hematopoietic stem cell transplantation in China: where we are and where to go
}

\author{
Meng LV and Xiao-Jun Huang
}

\begin{abstract}
Allogeneic hematopoietic stem cell transplantation (allo-HSCT) is an effective and sometimes the only curative therapy for patients with certain hematological diseases. Allo-HSCT has been practiced in China for approximately 30 years, and great improvements have been made within the past decade, particularly in fields such as the haploidentical HSCT system, strategies to overcome relapse and GVHD, and modified HSCT for elderly patients. This review will describe the current situation and provide a prospective of these unique aspects of Allo-HSCT in China.
\end{abstract}

Keywords: China, Allo-HSCT, Haploidentical, Relapse, GVHD, Elderly patients

\section{Current status of Allo-HSCT in China}

It has been more than thirty years since the first allogeneic bone marrow transplantation was successfully performed in China [1], and during the past decades, substantial progress has been made in the field of allogeneic hematopoietic stem cell transplantation (alloHSCT).

Currently, there are 104 transplant units certified by China's Ministry of Health and the China Marrow Donor Program. Of these centers, $60 \%$ are active and routinely perform HSCT. According to data collected from 50 active centers by the Chinese Hematopoietic Stem Cell Transplantation Registry Group (2007-2011), 5 centers performed more than 100 HSCT cases annually, and approximately 30 centers performed 20-100 cases per year. The total number of HSCT cases in all 50 active centers increased steadily from 1093 cases in 2007 to 1633 cases in 2010 [2]. By the end of 2011, this figure has been greater than 2000 by the preliminary statistics.

The types of donor sources for Allo-HSCT in China are related identical (47.3\%), related mismatched/haploidentical (30.8\%), unrelated matched (12.1\%), unrelated mismatched (7.7\%), umbilical cord blood (UCB, 2.2\%) and Allo-HSCT accounts for $91 \%$ of the total HSCT cases.

\footnotetext{
* Correspondence: xjhrm@medmail.com.cn

Peking University People's Hospital, Peking University Institute of Hematology, Beijing Key Laboratory of Hematopoietic Stem Cell Transplantation, No. 11 Xizhimen South Street, Beijng 100044, China
}

(Figure 1) [2]. These data are quite different from those reported by the CIBMTR(Center for International Blood and Marrow Transplant Research), which show that autologous HSCT takes up 58\% of the total HSCT cases and that unrelated donors comprise nearly half of all the allogeneic HSCT graft sources in the USA. Data on haploidentical HSCT(Haplo-HSCT) cases are not available [3]. The distribution of diseases occurring in allogeneic transplant recipients is as follows: acute myeloid leukemia (AML) (34\%), acute lymphoblastic leukemia (ALL) (24\%), chronic myeloid leukemia (CML) (20\%), myelodysplastic syndrome (MDS) (7\%), aplastic anemia (AA) (7\%), Mediterranean anemia (MIA) (2\%), non-Hodgkin's lymphoma (NHL) (3\%), and other diseases (2\%) (Figure 2). The proportions of disease types receiving allo-HSCT are similar to those reported by the CIBMTR. However, although the overall number of allo-HSCT cases in CML patients has decreased gradually in recent years, these patients still make up a relatively large proportion of the total alloHSCT cases (approximately 20\%). This is due to the potential accumulated expenses of tyrosine kinase inhibitors for young CML patients as well as the significant survival advantage of allo-HSCT compared with imatinimb treatment for patients with AP CML [4].

\section{The unique characters of Chinese HSCT system}

Though research resources for HSCT in China are limited, for example, HSCT researchers are allotted only 


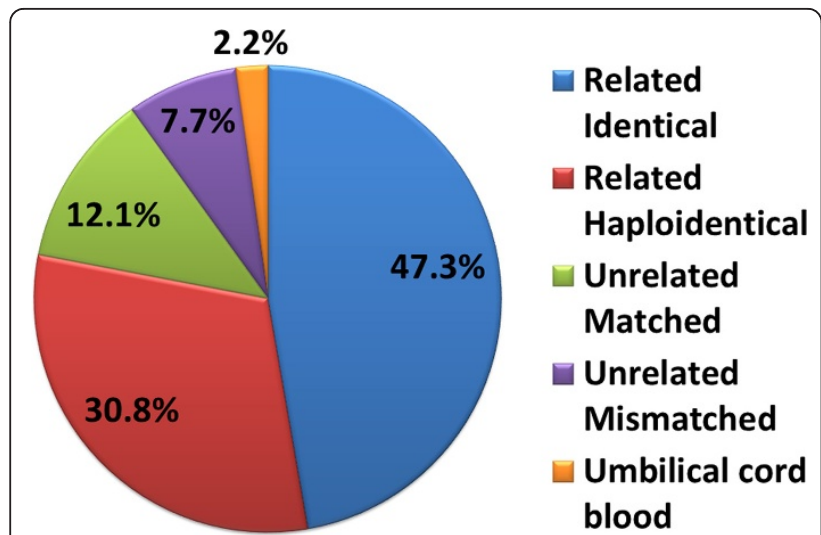

Figure 1 The types of donor sources for allo-HSCT in China.

$16 \%$ of the total financial support administered by the National Science Foundation in hematology, an increasing number of clinical and applied fundamental research studies in HSCT have been published in influential journals or presented orally at the American Society of Hematology (ASH) annual meeting. Also, HSCT in China is not just imitation, there are some characteristic aspects which may contribute to other HSCT programs around the world.

These unique characters of Chinese HSCT system can be divided into four categories: (1) Haplo-HSCT system, (2) strategies to overcome relapse and (3) GVHD, and (4) modified HSCT for elderly patients. The initiation of multi-center clinical trials and advances in translational research are important for promoting progress in HSCT methods in China.

Evidence-based and mechanism research on Haplo-HSCT Haplo-HSCT is one of the acceptable alternatives in the absence of HLA-matched siblings or unrelated donors

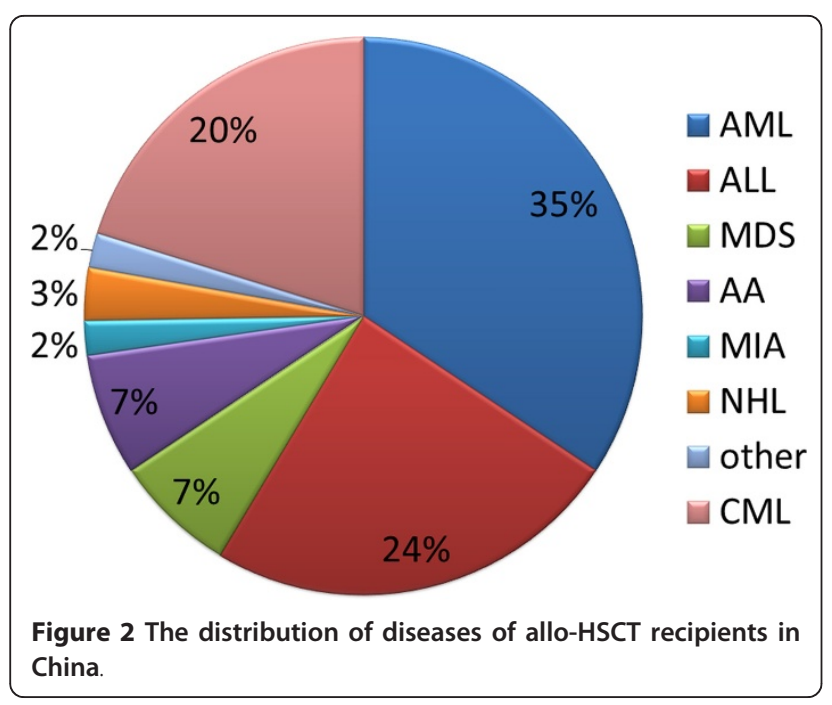

$[5,6]$. There are three main strategies to complete HaploHSCT: T cell-depleted myeloablative HSCT, unmanipulated myeloablative HSCT, or nonmyeloablative/reduced intensity conditioned HSCT [5,7]. Transplantation with $\mathrm{T}$ cell-depleted peripheral blood progenitor cells has a low rate of GVHD, but these transplants are associated with slow immune recovery, a high rate of relapse, and a substantial risk of treatment-related mortality [8]. Nonmyeloablative Haplo-HSCT shows relatively lower nonrelapse mortality but a higher rate of overall relapse [9]. The typical Haplo-HSCT systems around the world are summarized in (Table 1) [8-16].

Due to the "One Child Policy", there has been a shortage of HLA-identical siblings for Chinese patients who need HSCT; what's more, the donor pool of Chinese Marrow Donor Program and cord blood banks are still relatively small in view of the massive Chinese population [17], Therefore haplo-HSCT based on related family donors has a unique role in the treatment of hematologic disease in China. Peking University researchers developed a novel approach for HLA-mismatched/haploidentical myeloablative blood and marrow transplantation without in vitro $\mathrm{T}$ cell depletion within the past 10 years (the GIAC protocol). This protocol includes the following steps: treating donors with granulocyte colony-stimulating factor (G-CSF) to induce donor immune tolerance, intensified immunological suppression to both promote engraftment and prevent GVHD, antithymocyte globulin (ATG) administration for the prophylaxis of GVHD and graft rejection, and combination of G-CSF-primed bone marrow harvest (G-BM) and G-CSF-mobilized peripheral blood stem cell harvest (G-PB) as the source of stem cell grafts [18-21]. A singlecenter study reported that unmanipulated myeloablative HSCT using the GIAC protocol has similar LFS/grade, IIIIVaGVHD/extensive, chronic GVHD compared with HLA-matched sibling transplantation or matched unrelated donor transplantation [19,21]. The GIAC protocol also demonstrated improved GVL effects [22]. Also, modified haploidentical nonmyeloablative transplantation without $\mathrm{T}$ cell depletion and haploidentical PBSCT have been successfully launched as routine procedures in other centers in China [16,23]. Besides Hematological malignancies, haplo-HSCT has become a feasible and safe treatment for nonmalignant hematological diseases, such as severe aplastic anemia [24]. Based on the extensive application, together with unique immunomodulatory strategies for relapse (Referred to 2.2) and mechanism researches, haploHSCT of China has developed to a characteristic system. To date, haplo-HSCT accounts for approximately $30 \%$ of the total allo-HSCT cases per year in China, and in some experienced centers, such as Peking University Institute of Hematology, this proportion has consistently exceeded $60 \%$, and the cumulative haploidentical cases increased to more than 1300 in single center at the end of 2011. 
Table 1 Studies on Haploidentical Hematopoietic Stem Cell Transplantation

\begin{tabular}{|c|c|c|c|c|c|c|c|c|c|c|c|}
\hline $\begin{array}{l}\text { Patients } \\
\text { (n) }\end{array}$ & Disease & Conditioning & Graft/ Manipulation & GVHD Prophylaxis & GF & aGVHD & cGVHD & TRM & LFS/DFS & Nation & Reference \\
\hline 104 & $\mathrm{AL}$ & $\begin{array}{l}\text { ST:TBI/thiotepa/ } \\
\text { fludarabine/ATG }\end{array}$ & PB/CD34+ selection & No & $\begin{array}{l}1 s t \\
6.9 \%\end{array}$ & $\begin{array}{l}(\mathrm{II}-\mathrm{IV}) \\
7.9 \%\end{array}$ & $7.1 \%$ & $36.5 \%$ & AL CR:46\%-48\% & Italy & $\begin{array}{l}\text { Aversa } \\
(2005)[8]\end{array}$ \\
\hline 49 & $\begin{array}{l}\text { AL/MDS/ CML/ } \\
\text { MPD }\end{array}$ & RIC: Flu+Cy/ anti-CD52 & PB/anti-CD52 & $\mathrm{CsA}+\mathrm{MMF}$ & $6 \%$ & $(I I-I V) 16 \%$ & $14 \%$ & $10.2 \%$ & 31-63\%@1-3 year & U.S.A & $\begin{array}{l}\text { Rizzieri } \\
(2007)[10]\end{array}$ \\
\hline 24 & $\mathrm{AL} / \mathrm{AA}$ & ST:TBI/CY & $\begin{array}{l}\text { BM/costimulatory } \\
\text { blockade }\end{array}$ & $\mathrm{CsA}+\mathrm{MTX}$ & $5 \%$ & $\begin{array}{l}(I I I-I V) \\
23.8 \%\end{array}$ & $8.3 \%$ & $50 \%$ & 33\%@7 years & U.S.A & $\begin{array}{l}\text { Guinan } \\
\text { (2008)[11] }\end{array}$ \\
\hline 60 & $\begin{array}{c}\mathrm{AL} / \mathrm{NHL} / \mathrm{CML} / \\
\mathrm{MM}\end{array}$ & $\begin{array}{l}\text { RIC:Flu/Mel/OKT-3/ } \\
\text { thiotepa }\end{array}$ & $\begin{array}{c}\mathrm{PB} / \mathrm{CD} 3+\mathrm{CD} 19 \\
\text { depletion }\end{array}$ & $\begin{array}{c}\text { No if } C D 3+T<5 \times \\
104 / \mathrm{kg}\end{array}$ & 0 & $(\mathrm{II}-\mathrm{IV}) 47 \%$ & $15 \%$ & $\begin{array}{c}\text { 25\%@100 } \\
\text { days } \\
\text { 44\%@7 } \\
\text { years }\end{array}$ & $\begin{array}{c}\text { HR 41\%@1 year 24\%@2 } \\
\text { years }\end{array}$ & Germany & $\begin{array}{c}\text { Federmann } \\
(2009)[12]\end{array}$ \\
\hline 66 & AL/MDS & $\begin{array}{l}\text { RIC:TBI/flu/Bu/ATG/ } \\
\text { melphalan }\end{array}$ & $\mathrm{PB}$ or $\mathrm{BM} / \mathrm{No}$ & FK506 & $6.1 \%$ & $(\mathrm{II}-\mathrm{IV}) 38 \%$ & $33.3 \%$ & $59.1 \%$ & 28.8\%@4 years & Japan & $\begin{array}{l}\text { Kurokawa } \\
\text { (2010)[13] }\end{array}$ \\
\hline 820 & $\begin{array}{c}\mathrm{AL} / \mathrm{CML} / \mathrm{NHL} / \\
\mathrm{AA}\end{array}$ & $\begin{array}{c}\text { ST:Bu/Cy/Ara-C/MeCCNU/ } \\
\text { ATG }\end{array}$ & $\mathrm{BM}+\mathrm{PB} / \mathrm{No}$ & $\mathrm{CSA}+\mathrm{MTX}+\mathrm{MMF}$ & $<1 \%$ & $\begin{array}{c}(I I-I V) \\
42.9 \% \\
(I I I-I V) \\
14.0 \%\end{array}$ & $\begin{array}{c}\text { Total } \\
53.7 \% \\
\text { Ex } 23.4 \% \\
\text { @2 years }\end{array}$ & $\begin{array}{c}21 \% @ 2 \\
\text { years }\end{array}$ & $\begin{array}{l}\text { SR68.1\% HR47.1\% } \\
\text { @2 years }\end{array}$ & China & $\begin{array}{c}\text { Huang } \\
\text { (2011)[14] }\end{array}$ \\
\hline 83 & AL/MDS & RIC:Bu/Flu/ATG & $\mathrm{PB} / \mathrm{No}$ & $\mathrm{CsA}+\mathrm{MTX}$ & 0 & $24 \%$ & $28 \%$ & 17\%@1 year & $\begin{array}{l}\text { AML/MDS } \\
\text { CR53\%-60\%; } \\
\text { AML RE9\% }\end{array}$ & Korea & $\begin{array}{c}\text { Lee } \\
(2011)[15]\end{array}$ \\
\hline 50 & AL/MDS & RIC:Cy/Flu/TBI & $\mathrm{BM} / \mathrm{No}$ & $\mathrm{Cy}(\mathrm{HD})+\mathrm{FK} 506+\mathrm{MMF}$ & $4 \%$ & (II-IV)32\% & $13 \%$ & 7\%@1 year & 46\%@1 year & U.S.A & $\begin{array}{l}\text { Fuchs } \\
(2011)[9]\end{array}$ \\
\hline 21 & $\mathrm{AL} / \mathrm{CML}$ & $\mathrm{ST}: \mathrm{Bu} / \mathrm{Cy} / \mathrm{MeCCNU} / \mathrm{ATG}$ & $\mathrm{PB} / \mathrm{No}$ & CSA+MTX +MMF & 0 & $\begin{array}{l}(I I-I V) \\
33.8 \%\end{array}$ & $39.5 \%$ & $\begin{array}{c}\text { 20\%@2 } \\
\text { years }\end{array}$ & 55.6\%@2 years & China & $\begin{array}{c}Y u \\
(2012)[16]\end{array}$ \\
\hline
\end{tabular}

HLA Human leukocyte antigen; AL Acute Leukemia; CML chronic myelogenous leukemia; MDS myelodysplastic syndrome; ST Standard intensity/Myeloablative; RIC reduced intensity; Bu Busulfan; Cy cyclophosphamide; Ara-C aracytidine; TBI total-body irradiation; MeCCNU Semustine; CSA cyclosporine A; MMF Mycophenolate mofetil; Flu fludrabine; ATG antithymocyte globulin; FK506 Tacrolimus; anti-CD52 alemtuzumab; GF graft failure; HR high risk; SR standard risk; Re refractory; Ex extensive; GVHD Graft versus host disease 
Though the HLA polymorphism of China is more heterogeneous than that of Japan and Korea, as there are 56 different nationalities in China and the main nationality "Han" also varies in HLA alleles across the vast mainland [25-28]; Haplo-HSCT become more popular in China because of both the well-established clinical regimen and the shortage of sibling and unrelated donors, whereas Japan and Korea marrow donor program have satisfied the need for donors in their countries [26]. What's more, the HLA polymorphism of continental Northeast Asia varies similar to that of Europe and North America [29], which suggest experience of haplo-HSCT in China may be exportable in Europe and North America.

Nevertheless, there are still several problems confronting the future development of haplo-HSCT. First, although the underlying mechanism of crossing the HLA barrier has been partially explained by a series of in vitro and in vivo studies: (1) G-CSF leads to $\mathrm{T}$ cell hyporesponsiveness and modulates the balance between Th1 and Th2 immune responses [30]; (2)G-CSF treatment significantly decreased the expression of VLA-4, ICAM-1, L-selectin, and LFA- 1 on naïve CD4 ${ }^{+}$and $\mathrm{CD} 8+\mathrm{T}$ cells in bone marrow grafts. It was also found easier to polarize $\mathrm{T}$ cells from Th1 to Th2 in G-BM compared with G-PB [31]; (3) T cell hyporesponsiveness and polarization of $\mathrm{T}$ cell from Th1 to Th2 could be maintained after in vitro mixture of G-PB and G-BM, besides the benefits of independent component [32]. (4)Depletion of infused donor lymphocytes in vivo by ATG, and induction of regulatory T cells [33], etc. However, the complete story has not yet been elucidated. For example, in contrast with ex vivo $\mathrm{T}$ cells depletion haplo-HSCT model [34], our finding showed that KIR ligand mismatch is associated with higher aGVHD, a greater relapse rate and inferior survival in our unmanipulated HSCT system [35]; additional results suggested that NK cell allo-reactivity could be covered by massive T cells [36], which need further investigation. Second, reports from single centers are not as convincing as those from multi-center clinical trials. Evaluating a uniform haplo-HSCT protocol, such as GIAC, in more Chinese clinical centers would enable prospective, multicenter trials on the standardized treatment. These types of studies would hopefully aid in evaluating the roles of haplo-HSCT in some uncertain situations.

\section{Mechanism and management of relapse after HSCT}

Relapsing hematologic malignancy after HSCT remains a major cause of death for patients, and finding methods to trigger a more potent graft-versus-tumor effect without increasing the risk of GVHD is still the ultimate goal of HSCT. Many Chinese researchers have attempted to address this challenge.

In a recent study, Huang and his colleagues provide the first report of multiple mutations of CEBPA that contribute to the transformation of donor cells to the leukemic phenotype and provide clues of relapse from donor origin. Huang found that after the first genetic mutation involved in leukemogenesis occurs in the donor, the susceptible donor cells can acquire second or third mutations in different genes or recessive mutations in a single gene after transplantation to the recipient's particular microenvironment. This acquisition of mutations can lead to overt leukemic transformation and cause relapse. This mechanism provides a unique viewpoint that aids our understanding of the process of relapse due to the "multiple genetic-hits mechanism" and suggests that the targeting of mutated genes may be a possible strategy to prevent relapse [37]. Meanwhile, Diamond et al. found relapse of AML after allo-HSCT from donor origin who harbors germline XPD and XRCC3 polymorphisms resulting in low DNA repair capacity [38]. These research together emphasize the importance of gene polymorphisms in selecting candidate donors prior to allo-HSCT.

There is a large gap between laboratory research and clinical application; however, by integrating minimal residual disease (MRD) monitoring and modified donor lymphocyte infusion (mDLI), researchers at Peking University have improved the management of relapse following HSCT in the clinic [39]. Traditional DLI with steady-state lymphocytes has been shown to effectively treat relapse, but it often causes severe GVHD [40]. However, data from other study showed that replacing steady-state lymphocytes with G-PB and applying a short course of immunosuppressive agents (administration of CSA or MTX after DLI for 2-4 weeks) reduced the incidence of DLI-associated acute GVHD without affecting relapse or survival [41]. For patients with hematological relapse after receiving allo-HSCT, the donor GPBPC infusion treatment group had a better outcome compared with chemotherapy; this finding has been demonstrated in both patients under HLA-matched and HLA-mismatched/haploidentical T-cell-replete HSCT groups $[42,43]$. A later study demonstrated that mDLI treatment also had a prophylactic effect against relapse in high-risk leukemia patients after either of these types of HSCT $[44,45]$. Recently, our team concluded that risk stratification-directed interventions with $\mathrm{mDLI}$ in MRD-positive patients with standard-risk acute leukemia could prevent leukemia relapse and further improve transplant outcomes [46]. Based on these findings, a series of clinical and basic studies were initiated to separate the GVL effect from GVHD with modified DLI in patients with hematological malignancies. These studies found that GPBPC harvests contained more CD34+ cells, Th2-type cells and type II cytokines than non-primed peripheral lymphocyte harvests, which contribute to the lower incidence of aGVHD [32,47]. Meanwhile, the type I cytokines, like IFN- $\gamma$, was kept and capable of promoting 
GVL effects via mechanisms independent of its interaction with leukemia cells [48]. However, the effects of shortcourse immunosuppressive agents on these lymphocytes remain to be evaluated.

\section{Prophylaxis and Management of GVHD}

GVHD is the main complication post-HSCT, and Chinese doctors must address this condition due to the high proportion of haplo-HSCT cases. Thus, several novel strategies to prevent GVHD have been devised.

The application of low-dose MTX has been demonstrated as a novel regimen for the treatment of GVHD by Peking University research group in different studies. Data from a recent report suggested that MTX in combination with low-dose methylpredinisone was well-tolerated and effective when used as the first-line treatment for aGVHD [49]. It has also been suggested that MTX is a well-tolerated, effective, and inexpensive agent when used as a firstline treatment in combination with other immunosuppressive agents for cGVHD, especially for skin or single organ involvement without concomitant thrombocytopenia [50]. This finding is also supported by a consensus on clinical practices in CGVHD [51].

Lai et al. recently described the efficacy of a new GVHD prophylaxis regimen that combines CSA and MTX with a short 30-day course of low-dose $(500 \mathrm{mg} / \mathrm{d})$ mycophenolate mofetil. After allo-HSCT with identical sibling donors, the incidence of acute GVHD was 16\% (9.5\% for grades $2-4$ GVHD and $1 \%$ for grades 3 and 4 GVHD). The cumulative incidence of chronic GVHD was 53\%, and $28 \%$ of these patients experienced the extensive type of disease [52]. Xia et al. reported that basiliximab has a similar effect on aGVHD but superior activity against cGVHD compared with daclizumab [53].

Nevertheless, most of the studies mentioned above are retrospective, and thus, further prospective and multi-center, randomized, controlled studies are needed.

In addition to drugs and antibodies, immunomodulatory cell transfusion may be a more specific method to protect patients from GVHD. Chen et al. reported that heterogenetic bone marrow mesenchymal stem cells (MSCs) could suppress $\mathrm{T}$ cell activation. MSC pretreatment was useful in the prevention of GVHD in HLA-mismatched bone marrow transplantation [54]. Xiang et al. reported transfusion of MSCs expanded from the BM of volunteers in vitro was a safe and effective salvage therapy for patients with steroid-resistant cGVHD, which might be mediate by increasing ratio of CD5 + CD19+/CD5-CD19+ regulatory B cells and CD8 + CD28-/CD8 + CD28+ T cells [55]. However, the cotransplantation of MSCs and HSCs may prevent GVHD while elevating the risk of relapse and therefore must be handled with extreme caution.

Basic and Pre-clinical researches on GVHD have also been highly regarded in China. Zhao showed blockade of
osteopontin(OPN) could reduce alloreactive CD8+ $\mathrm{T}$ cell-mediated GVHD in animal model: OPN promoted the migration and infiltration of naive and alloreactive CD8(+) T cells into host organs; it also facilitated activation and viability of donor-derived CD8(+) T cells via synergizing with CD3 signaling. This findings could validate OPN as a potential target in GVHD prevention [56]. As mentioned above, MMF is an important regimen in controlling GVHD, yet the therapeutic effect of MMF varies in patients. Huang et al. firstly reported the presence of the IMPDH1 IVS8-106 G/G genotype of Inosine monophosphate dehydrogenase (IMPDH, target enzyme of MMF) in recipients was associated with a significantly higher incidence of aGVHD than other genotypes, in both unrelated and sibling transplantation cohorts [57]. This finding would contribute to the individualized therapy of GVHD according to gene polymorphism.

There are also many promising pre-clinical studies focused on the potential application of immune cells in controlling GVHD, such as umbilical cord blood (CB) derived stromal cells [58], ex vivo expanded CB CD4 + CD25+ Foxp 3+ regulatory T cells [59], as well as CXCR4transduced MSCs, which maintained their immunosuppressive capacity and showed enhanced migration capacity in vitro, thus controlled the occurrence of GVHD more effectively [60].

In short, the progression of these basic and pre-clinical studies would hopefully ameliorate the clinic practices of controlling GVHD in near future.

\section{Modified HSCT for elderly patients}

The outcome of transplantation in patients older than 60 years of age remains unsatisfactory with a low complete remission (CR) rate and poor overall survival (OS) due to prolonged pancytopenia and an elevated chemotherapyrelated mortality, etc. [61]. Allogeneic stem cell transplantation after nonmyeloablative or reduced intensity conditioning shows some curative effects for acute leukemia in elderly patients; however, the transplant comorbidities associated with GVHD and infection remain obstacles for this population [62].

Mouse models infused with high doses of G-CSF-mobilized allogeneic spleen cells after cytarabine chemotherapy without immunosuppressive pretreatment exhibited rapid hematopoietic recovery and persistent microchimerism without GVHD. Ai and colleagues designed a clinical control study to show the superiority of "miniHSCT" over chemotherapy for elderly patients suffering from AML. This HSCT protocol mainly consisted of induction chemotherapy plus the infusion of HLA-mismatched G-PBSCs. Patients who received this treatment had a higher complete remission rate and disease-free survival over 2 years with no observable GVHD. These results indicate that G-PBSCs in combination with 
conventional chemotherapy may provide a promising treatment method for AML in elderly patients. This finding warrants further multi-center studies to confirm the results and determine if the same method can be applied in the treatment of ALL or other hematopoietic malignancies [63]. Besides, mechanism of "mini-HSCT" remains to be investigated.

\section{Prospects for the HSCT in China}

As mentioned above, multi-center prospective studies and researches connecting "bench to bed" are essential to promote the development of HSCT in China. Actually, there have been successful multi-center trials conducted in general hematology and molecular diagnostics, such as the prospective study "Molecular Diagnosis and Individualized Treatment of Acute Leukemia" supported by the National High Technology Research and Development Program (Program 863). Nevertheless, many challenges remain in the HSCT field: (1) Compared with many well developed international registries, for example, the European Group for Blood and Marrow Transplantation (EBMT), the Chinese Hematopoietic Stem Cell Transplantation Association must make considerable progress in establishing itself as a leader in clinical trials in addition to its role in data management [2]. (2) Standardization would contribute to the improvement and modification of the entire system by allowing results from multiple centers to be compared. However, standardized practices are associated with more precise diagnoses, risk stratification, and corresponding individualized treatment rather than solitary therapies that vary from center to center. The dissemination of techniques is more difficult from experienced centers to smaller HSCT units due to the complexity of the HSCT system, which requires more experienced doctors and diagnostic technologies. (3) Benefit-sharing mechanisms are essential to the success of multi-center clinical trials. A well-developed system would allow all participating units to access data and analyze results from different angles. On the other hand, some experienced centers or institutes have the responsibility to lead clinical research programs applying for financial support, such as the key programs 973 and 863 of China, and to develop well-organized trials.

Next, two strategies can be employed to promote the connection between basic research and clinical practice in the field of Chinese HSCT. Firstly, Chinese researchers must make significant progress in identifying the underlying mechanisms of well-developed clinical models, such as haplo-HSCT. This unique diagnosis and treatment system in turn provides a perfect opportunity to analyze and compare the differences among clinical and animal models. Secondly, translational researchers must pursue promising cellular or animal experiments. For example, researchers from Jilin University, China, found that IFN $-\gamma$ promotes graft-versus-leukemia effects without directly interacting with leukemia cells in mice after HSCT [48]. Therefore, it would be very interesting to investigate the potential enhancement of GVL effects in DLI or reduced intensity HSCT in patients by manipulation of IFN- $\gamma$.

In summary, it would be very meaningful for Chinese scholars to participate in translational researches of clinical significance, such as immune tolerance in HLA-mismatched HSCT, the distinction between GVHD and GVL, and the association between infection and chronic immunologic imbalance.

\section{Conclusion}

China has made substantial progress in the field of alloHSCT during the past three decades, particularly in the clinical applications and mechanism researches of haplo-HSCT system, strategies to overcome relapse and GVHD, and modified HSCT for elderly patients. With the development of multi-center clinical trials and advances in translational research, these unique fields of allo-HSCT in China will have a promising future and contribute more to the world HSCT system.

\section{Abbreviations}

HSCT: Hematopoietic stem cell transplantation; BMT: bone marrow transplantation; GVHD: Graft versus host disease; CIBMTR: Center for International Blood and Marrow Transplant Research; Allo: Allogeneic; ATG: Antithymocyte globulin; G-BM: G-CSF-primed bone marrow harvest; G-PB: GCSF-mobilized peripheral blood stem cell harvest; MRD: Minimal residual disease; mDLI: Modified donor lymphocyte infusion; MSCs: Mesenchymal stem cells; CR: Complete remission; OS: Overall survival

\section{Acknowledgements}

This study was supported by grants from National Natural Science Foundation of China(Grant No. 30971292), Doctoral Fund of Ministry of Education of China(Grant No. 20110001110039$)$, Natural Science Foundation of Beijing(Grant No. 7122193).

\section{Authors' contributions}

$\mathrm{ML}$ collected data and wrote the manuscript, XJH designed and revised the manuscript. All authors read and approved the final manuscript.

\section{Competing interests}

The authors declare that they have no competing interests.

Received: 9 February 2012 Accepted: 18 March 2012

Published: 18 March 2012

\section{References}

1. Lu DP, Guo NL, Jin NR, Zheng H, Lu XJ, Shi Q, Shan FX, Jiang B, Tang H, Liu MY: Allogeneic bone marrow transplantation for the treatment of leukemia. Chin Med J (Engl) 1990, 103:125-130.

2. Xu LP, Huang XJ: Current status and development of hematopoietic stem cell transplantation in China: a report from Chinese Hematopoietic Stem Cell Transplantation Register Group. Chin Med J (Engl) 2011, 124:2548-2555.

3. Pasquini MCWZ: Current use and outcome of hematopoietic stem cell transplantation: CIBMTR Summary Slides, 2011.[http://www.cibmtr.org].

4. Jiang $Q$, Xu LP, Liu DH, Liu KY, Chen SS, Jiang B, Jiang H, Chen H, Chen YH, Han W, et al: Imatinib mesylate versus allogeneic hematopoietic stem cell transplantation for patients with chronic myelogenous leukemia in the accelerated phase. Blood 2011, 117:3032-3040.

5. Huang XJ: Current status of haploidentical stem cell transplantation for leukemia. J Hematol Oncol 2008, 1:27. 
6. Fuchs EJ, Huang XJ, Miller JS: HLA-haploidentical stem cell transplantation for hematologic malignancies. Biol Blood Marrow Transplant 2010, 16 : S57-S63.

7. Reisner Y, Hagin D, Martelli MF: Haploidentical hematopoietic transplantation: current status and future perspectives. Blood 2011, 118:6006-6017

8. Aversa F, Terenzi A, Tabilio A, Falzetti F, Carotti A, Ballanti S, Felicini R, Falcinelli $F$, Velardi A, Ruggeri $L$, et al: Full haplotype-mismatched hematopoietic stem-cell transplantation: a phase II study in patients with acute leukemia at high risk of relapse. J Clin Oncol 2005, 23:3447-3454.

9. Brunstein CG, Fuchs EJ, Carter SL, Karanes C, Costa LJ, Wu J, Devine SM, Wingard JR, Aljitawi OS, Cutler CS, et al: Alternative donor transplantation after reduced intensity conditioning: results of parallel phase 2 trials using partially HLA-mismatched related bone marrow or unrelated double umbilical cord blood grafts. Blood 2011, 118:282-288.

10. Rizzieri DA, Koh LP, Long GD, Gasparetto C, Sullivan KM, Horwitz M, Chute J, Smith C, Gong JZ, Lagoo A, et al: Partially matched, nonmyeloablative allogeneic transplantation: clinical outcomes and immune reconstitution. J Clin Oncol 2007, 25:690-697.

11. Davies JK, Gribben JG, Brennan LL, Yuk D, Nadler LM, Guinan EC: Outcome of alloanergized haploidentical bone marrow transplantation after ex vivo costimulatory blockade: results of 2 phase 1 studies. Blood 2008, 112:2232-2241

12. Federmann B, Bornhauser M, Kordelas L, Beelen DW, Stuhler $G$, Schwerdtfeger R, Stelljes M, Behre G, Christopeit M, Faul C, et al: Results of a Phase II Study of Haploidentical Hematopoietic Cell Transplantation (HHCT) in Adults Using Reduced Intensity Conditioning and CD3/CD19Depleted Grafts: clinical outcome and immune reconstitution. ASH Annual Meeting Abstracts 2009, 114:1203

13. Kurokawa T, Ishiyama K, Ozaki J, Yamashita Y, Iwaki N, Saito C, Arahata M, Kaya H, Yoshida T: Haploidentical hematopoietic stem cell transplantation to adults with hematologic malignancies: analysis of 66 cases at a single Japanese center. Int J Hematol 2010, 91:661-669.

14. Huang XJ: Long Term Follow-up of Haploidentical Hematopoietic Stem Cell Transplantation without in Vitro T Cell Depletion for the Treatment of Hematological Malignancies: 9-Year Experience of a Single Center. ASH Annual Meeting Abstracts 2011, 118:839.

15. Lee KH, Lee JH, Kim DY, Seol M, Lee YS, Kang YA, Jeon M, Hwang HJ, Jung AR, Kim SH, et al: Reduced-intensity conditioning therapy with busulfan, fludarabine, and antithymocyte globulin for HLA-haploidentical hematopoietic cell transplantation in acute leukemia and myelodysplastic syndrome. Blood 2011, 118:2609-2617.

16. Huang W, Li H, Gao C, Bo J, Wang Q, Zhao Y, Jing Y, Wang S, Zhu H, Dou $L$, et al: Unmanipulated HLA-mismatched/haploidentical peripheral blood stem cell transplantation for high-risk hematologic malignancies. Transfusion 2012, doi: 10.1111/j.1537-2995.2011.03478.x.

17. Hong JL: A brief introduction of the Chinese Marrow Donor Program. Hong Kong Med J 2009, 15:45-47.

18. Huang XJ, Liu DH, Liu KY, Xu LP, Chen H, Han W, Chen YH, Wang JZ, Gao ZY, Zhang YC, et al: Haploidentical hematopoietic stem cell transplantation without in vitro T-cell depletion for the treatment of hematological malignancies. Bone Marrow Transplant 2006, 38:291-297.

19. Lu DP, Dong L, Wu T, Huang XJ, Zhang MJ, Han W, Chen H, Liu DH, Gao ZY, Chen YH, et al: Conditioning including antithymocyte globulin followed by unmanipulated HLA-mismatched/haploidentical blood and marrow transplantation can achieve comparable outcomes with HLAidentical sibling transplantation. Blood 2006, 107:3065-3073.

20. Xiao-Jun H, Lan-Ping X, Kai-Yan L, Dai-Hong L, Huan C, Wei H, Yu-Hong C, Jing-Zhi W, Yao C, Xiao-Hui Z, et al: HLA-mismatched/haploidentical hematopoietic stem cell transplantation without in vitro $\mathrm{T}$ cell depletion for chronic myeloid leukemia: improved outcomes in patients in accelerated phase and blast crisis phase. Ann Med 2008, 40:444-455.

21. Xiao-Jun H, Lan-Ping X, Kai-Yan L, Dai-Hong L, Yu W, Huan C, Yu-Hong C, Wei $\mathrm{H}$, Jing-Zhi W, Yao C, et al: Partially matched related donor transplantation can achieve outcomes comparable with unrelated donor transplantation for patients with hematologic malignancies. clin cancer res 2009, 15:4777-4783.

22. Wang Y, Liu DH, Xu LP, Liu KY, Chen H, Chen YH, Han W, Shi HX, Huang XJ: Superior graft-versus-leukemia effect associated with transplantation of haploidentical compared with HLA-identical sibling donor grafts for high-risk acute leukemia: an historic comparison. Biol Blood Marrow Transplant 2011, 17:821-830.

23. Guo M, Sun Z, Sun QY, Han Q, Yu CL, Wang DH, Qiao JH, Chen B, Sun WJ, Hu KX, et al: A modified haploidentical nonmyeloablative transplantation without $\mathrm{T}$ cell depletion for high-risk acute leukemia: successful engraftment and mild GVHD. Biol Blood Marrow Transplant 2009, 15:930-937.

24. Han W, Huang XJ, Liu KY, Xu LP, Liu DH, Chen H, Zhang XH, Chen YH, Wang FR, Wang Y: The efficacy and safety of mismatched hematopoietic stem cell transplantation for treatment of severe aplastic anemia. Zhonghua Nei Ke Za Zhi 2011, 50:287-290.

25. Lee KW, Oh DH, Lee C, Yang SY: Allelic and haplotypic diversity of HLA-A, $-B,-C,-D R B 1$, and $-D Q B 1$ genes in the Korean population. Tissue Antigens 2005, 65:437-447.

26. Okamoto S: Current status of Japan marrow donor program (JMDP) and its roles in international cooperation. Int J Hematol 2002, 76(Suppl 1):310-311.

27. Trachtenberg E, Vinson M, Hayes E, Hsu YM, Houtchens K, Erlich H, Klitz W, Hsia Y, Hollenbach J: HLA class I (A, B, C) and class II (DRB1, DQA1, DQB1, DPB1) alleles and haplotypes in the Han from southern China. Tissue Antigens 2007, 70:455-463.

28. Wu GG, Deng ZH, Gao SQ, Cheng LH, Jin SZ, Zhou D, Li Z, Zou HY, Zhang X, Wei TL, et al: Study of HLA polymorphism in the $6965 \mathrm{Han}$ bone marrow registry donors. Zhonghua Xue Ye Xue Za Zhi 2004, 25:473-477.

29. Buhler S, Sanchez-Mazas A: HLA DNA sequence variation among human populations: molecular signatures of demographic and selective events. PLoS One 2011, 6:e14643.

30. Jun $H X$, Jun $C Y$, Yu ZX: In vivo induction of T-cell hyporesponsiveness and alteration of immunological cells of bone marrow grafts using granulocyte colony-stimulating factor. Haematologica 2004, 89:1517-1524.

31. Jun $H X$, Jun $C Y$, Yu ZX: A direct comparison of immunological characteristics of granulocyte colony-stimulating factor (G-CSF)-primed bone marrow grafts and G-CSF-mobilized peripheral blood grafts. Haematologica 2005, 90:715-716.

32. Huang XJ, Chang YJ, Zhao XY: Maintaining hyporesponsiveness and polarization potential of T cells after in vitro mixture of G-CSF mobilized peripheral blood grafts and G-CSF primed bone marrow grafts in different proportions. Transpl Immunol 2007, 17:193-197.

33. Feng X, Kajigaya S, Solomou EE, Keyvanfar K, Xu X, Raghavachari N, Munson PJ, Herndon TM, Chen J, Young NS: Rabbit ATG but not horse ATG promotes expansion of functional CD4 + CD25highFOXP3+ regulatory T cells in vitro. Blood 2008, 111:3675-3683.

34. Ruggeri L, Capanni M, Urbani E, Perruccio K, Shlomchik WD, Tosti A, Posati S, Rogaia D, Frassoni F, Aversa F, et al: Effectiveness of donor natural killer cell alloreactivity in mismatched hematopoietic transplants. Science 2002, 295:2097-2100.

35. Huang XJ, Zhao XY, Liu DH, Liu KY, Xu LP: Deleterious effects of KIR ligand incompatibility on clinical outcomes in haploidentical hematopoietic stem cell transplantation without in vitro T-cell depletion. Leukemia 2007, 21:848-851.

36. Chang YJ, Zhao XY, Huang XJ: Effects of the NK cell recovery on outcomes of unmanipulated haploidentical blood and marrow transplantation for patients with hematologic malignancies. Biol Blood Marrow Transplant 2008, 14:323-334.

37. Xiao H, Shi J, Luo Y, Tan Y, He J, Xie W, Zhang L, Wang Y, Liu L, Wu K, et al First report of multiple CEBPA mutations contributing to donor origin of leukemia relapse after allogeneic hematopoietic stem cell transplantation. Blood 2011, 117:5257-5260.

38. Diamond HR, Ornellas MH, Orfao A, Gomes BE, Campos MM, Fernandez TS, da Silva Rl, Alves G, Lage C, da Silva DA, et al: Acute myeloid leukemia of donor origin after allogeneic stem cell transplantation from a sibling who harbors germline XPD and XRCC3 homozygous polymorphisms. $J$ Hematol Oncol 2011, 4:39.

39. Huang XJ: Immunomodulatory strategies for relapse after haploidentica hematopoietic stem cell transplantation in hematologic malignancy patients. Best Pract Res Clin Haematol 2011, 24:351-358

40. Kolb HJ, Schattenberg A, Goldman JM, Hertenstein B, Jacobsen N, Arcese W, Ljungman P, Ferrant A, Verdonck L, Niederwieser D, et al: Graftversus-leukemia effect of donor lymphocyte transfusions in marrow grafted patients. Blood 1995, 86:2041-2050. 
41. Huang XJ, Wang Y, Liu DH, Xu LP, Liu KY, Chen H, Chen YH, Han W, Shi HX: Administration of short-term immunosuppressive agents after DLI reduces the incidence of DLI-associated acute GVHD without influencing the GVL effect. Bone Marrow Transplant 2009, 44:309-316.

42. Huang X, Guo N, Ren H, Zhang Y, Gao Z, Lu D: An improved anti-leukemic effect achieved with donor progenitor cell infusion for relapse patients after allogeneic bone marrow transplantation. Chin Med J (Engl) 2003, 116:736-741

43. Huang XJ, Liu DH, Liu KY, Xu LP, Chen H, Han W: Donor lymphocyte infusion for the treatment of leukemia relapse after HLA-mismatched/ haploidentical T-cell-replete hematopoietic stem cell transplantation. Haematologica 2007, 92:414-417.

44. Huang XJ, Liu DH, Xu LP, Chen H, Han W, Liu KY, Lu DP: Prophylactic infusion of donor granulocyte colony stimulating factor mobilized peripheral blood progenitor cells after allogeneic hematological stem cell transplantation in patients with high-risk leukemia. Leukemia 2006, 20:365-368.

45. Huang XJ, Liu DH, Liu KY, Xu LP, Chen YH, Wang Y, Han W, Chen H: Modified donor lymphocyte infusion after HLA-mismatched/ haploidentical T cell-replete hematopoietic stem cell transplantation for prophylaxis of relapse of leukemia in patients with advanced leukemia. $J$ Clin Immunol 2008, 28:276-283.

46. Yan CH, Liu DH, Liu KY, Xu LP, Liu YR, Chen H, Han W, Wang Y, Qin YZ, Huang XJ: Risk stratification-directed donor lymphocyte infusion could reduce relapse of standard-risk acute leukemia patients after allogeneic hematopoietic stem cell transplantation. Blood 2012, doi:10.1182/blood2011-09-380386.

47. Huang XJ, Wang Y, Liu DH, Xu LP, Chen H, Chen YH, Han W, Shi HX, Liu KY: Modified donor lymphocyte infusion (DLI) for the prophylaxis of leukemia relapse after hematopoietic stem cell transplantation in patients with advanced leukemia-feasibility and safety study. J Clin Immunol 2008, 28:390-397.

48. Yang $Y$, Wang $H$, Yu H, Yeap BY, Liang T, Wang G, Cheng T, Yang YG: IFNgamma promotes graft-versus-leukemia effects without directly interacting with leukemia cells in mice after allogeneic hematopoietic cell transplantation. Blood 2011, 118:3721-3724.

49. Wang Y, Xu LP, Liu KY, Liu DH, Wang J, Chen H, Chen YH, Han W, Huang XJ: Low-dose MTX combined with low-dose methylprednisolone as a first-line therapy for the treatment of acute GVHD: safety and feasibility. Bone Marrow Transplant 2011, 46:892-898.

50. Wang Y, Xu LP, Liu DH, Chen H, Chen YH, Han W, Liu KY, Huang XJ: Firstline therapy for chronic graft-versus-host disease that includes low-dose methotrexate is associated with a high response rate. Biol Blood Marrow Transplant 2009, 15:505-511.

51. Wolff D, Schleuning M, von Harsdorf S, Bacher U, Gerbitz A, Stadler M Ayuk F, Kiani A, Schwerdtfeger R, Vogelsang GB, et al: Consensus Conference on Clinical Practice in Chronic GVHD: Second-Line Treatment of Chronic Graft-versus-Host Disease. Biol Blood Marrow Transplant 2011, 17:1-17.

52. Lai Y, Ma J, Schwarzenberger P, Li W, Cai Z, Zhou J, Peng Z, Yang J, Luo L, Luo J, et al: Combination of CsA, MTX and low-dose, short-course mycophenolate mofetil for GVHD prophylaxis. Bone Marrow Transplant 2009, 43:61-67

53. Fang J, Hu C, Hong M, Wu Q, You Y, Zhong Z, Li W, Zou P, Hu Y, Xia L: Prophylactic Effects of Interleukin-2 Receptor Antagonists against Graftversus-Host Disease following Unrelated Donor Peripheral Blood Stem Cell Transplantation. Biol Blood Marrow Transplant 2011, doi:10.1016/j. bbmt.2011.09.005.

54. Ning $H$, Yang $F$, Jiang $M, H u L$, Feng $K$, Zhang J, Yu Z, Li B, Xu C, Li Y, et al: The correlation between cotransplantation of mesenchymal stem cells and higher recurrence rate in hematologic malignancy patients: outcome of a pilot clinical study. Leukemia 2008, 22:593-599.

55. Weng JY, Du X, Geng SX, Peng YW, Wang Z, Lu ZS, Wu SJ, Luo CW, Guo R, Ling $W$, et al: Mesenchymal stem cell as salvage treatment for refractory chronic GVHD. Bone Marrow Transplant 2010, 45:1732-1740.

56. Zhao F, Zhang Y, Wang H, Jin M, He S, Shi Y, Guo Y: Blockade of osteopontin reduces alloreactive CD8+ T cell-mediated graft-versus-host disease. Blood 2011, 117:1723-1733.

57. Cao W, Xiao H, Lai X, Luo Y, Shi J, Tan Y, Zheng W, He J, Xie W, Li L, et al: Genetic variations in the mycophenolate mofetil target enzyme are associated with acute GVHD risk after related and unrelated hematopoietic cell transplantation. Biol Blood Marrow Transplant 2012, 18:273-279.

58. Zhang C, Chen XH, Zhang X, Gao L, Kong PY, Peng XG, Liang X, Gong Y, Wang QY: Human umbilical cord blood-derived stromal cells, a new resource in the suppression of acute graft-versus-host disease in haploidentical stem cell transplantation in sublethally irradiated mice. $J$ Biol Chem 2011, 286:13723-13732.

59. Yang J, Fan H, Hao J, Ren Y, Chen L, Li G, Xie R, Yang Y, Qian K, Liu M: Amelioration of acute graft-versus-host disease by adoptive transfer of ex vivo expanded human cord blood CD4 + CD25+ forkhead box protein $3+$ regulatory $T$ cells is associated with the polarization of Treg/ Th17 balance in a mouse model. Transfusion 2011, doi: 10.1111/j.15372995.2011.03448.x.

60. Chen W, Li M, Li Z, Yan Z, Cheng H, Pan B, Cao J, Chen C, Zeng L, Xu K: CXCR4-transduced mesenchymal stem cells protect mice against graftversus-host disease. Immunol Lett 2012, doi:10.1016/j.imlet.2012.01.015.

61. Marks DI: Treating the "older" adult with acute lymphoblastic leukemia. Hematology Am Soc Hematol Educ Program 2010, 2010:13-20.

62. Estey E, de Lima M, Tibes R, Pierce S, Kantarjian H, Champlin R, Giralt S: Prospective feasibility analysis of reduced-intensity conditioning (RIC) regimens for hematopoietic stem cell transplantation (HSCT) in elderly patients with acute myeloid leukemia (AML) and high-risk myelodysplastic syndrome (MDS). Blood 2007, 109:1395-1400.

63. Guo M, Hu KX, Yu CL, Sun QY, Qiao JH, Wang DH, Liu GX, Sun WJ, Wei L, Sun $X D$, et al: Infusion of HLA-mismatched peripheral blood stem cells improves the outcome of chemotherapy for acute myeloid leukemia in elderly patients. Blood 2011, 117:936-941.

doi:10.1186/1756-8722-5-10

Cite this article as: LV and Huang: Allogeneic hematopoietic stem cell transplantation in China: where we are and where to go. Journal of Hematology \& Oncology 2012 5:10.

\section{Submit your next manuscript to BioMed Central and take full advantage of:}

- Convenient online submission

- Thorough peer review

- No space constraints or color figure charges

- Immediate publication on acceptance

- Inclusion in PubMed, CAS, Scopus and Google Scholar

- Research which is freely available for redistribution

Submit your manuscript at www.biomedcentral.com/submit
C) Biomed Central 